\title{
RESEARCH ON FACTORS INFLUENCING FERTILITY WILLINGNESS UNDER CHINA'S COMPREHENSIVE TWO-CHILD POLICY -- BASED ON LOGISTIC REGRESSION ANALYSIS
}

\author{
Si-kai Fu and Xu-fan Zhang \\ Ginling College, Nanjing Normal University, Nanjing 210097, Jiangsu, China \\ DOI: 10.46609/IJSSER.2021.v06i03.014 URL: https://doi.org/10.46609/IJSSER.2021.v06i03.014
}

\begin{abstract}
Since the promulgation of the comprehensive two-child policy, the achievements have not been remarkable. To explore the influencing factors of fertility willingness, binary logistic regression analysis was conducted based on CGSS2015 data. The results show that age, family population, social class after ten years, satisfaction with social management services, satisfaction with infrastructure construction, ownership of real estate and housing area have positive and significant influences on the fertility willingness, while education level and social security satisfaction have significant negative correlations on the fertility willingness of the sample group. Therefore, China needs to continue to improve the social security system, reduce the economic burden of group fertility and other measures to improve fertility willingness, change the low fertility rate and promote the long-term balanced development of population.
\end{abstract}

Key words: Comprehensive two-child policy; Fertility willingness; Binary logistic regression

\section{Introduction}

The development of a country is inseparable from the development of population quantity and quality, which is important for the government and scholars to study. The research on fertility willingness is an important basis for investigating the fertility level in the future, a social problem that has long been concerned by the state[1], and also a hot field of academic research. In the discussion of population fertility theory, scholars combine their own fields to build theoretical foundation. Leibenstein ${ }^{[2]}$ put forward the microeconomic theory based on "cost-utility", and adopted the "marginal children rational choice model" to compare the direct cost and indirect opportunity needed for childbirth with the potential utility in the future, and decide the number of children to have, Barber ${ }^{[3]}$ proposed the theory of fertility supply and demand to analyze the influence of fertility cost on fertility willingness, Becker's $[4]_{\text {theory of quantity-quality substitution }}$ 


\section{International Journal of Social Science and Economic Research}

ISSN: $2455-8834$

Volume:06, Issue:03 "March 2021"

and Caldwell's $[5]$ theory of intergenerational wealth flow can explain the continuous decline of fertility rate in most western countries since 1960s, and provide theoretical basis for studying fertility willingness underthe background of low fertility rate.

Since the beginning of the 21st century, the fertility concept of fewer and better births has gradually influenced China's fertility behavior due to changes in the endogenous motivation and external environmental factors [6]. However, With the acceleration of population aging process, a group of "421" family pattern with the one-child policy as the main core of the pension is gradually formed. Affected by theinverted pyramid family structure, it intensifies the pressure of future pension[7]. On January 1, 2016, the Chinese government officially implemented a comprehensive two-child birth policy, which marked that China's population development entered a relatively loose birth policy[8], with a view to solving the problems brought about by demographic changes such as aging, unbalanced sex ratio at birth, declining fertility rate and disappearing demographic dividend.

Under the background of comprehensive two-child policy, the birth rate in China in 2019 was only $10.48 \%$, a record low. Based on this, this paper puts forward a study on the restrictive factors of fertility willingness, makes an empirical analysis on fertility willingness by using CGSS data in 2015, and fully discusses and analyzes the internal motivation and external factors that affect fertility willingness, so as to provide reference for improving fertility rate and guiding people to increase fertility willingness.

\section{Literature Review}

In the study of demographic characteristics, women's childbearing age played a greater role in influencing factors of fertility willingness in the comparison of sample fertility willingness under the background of one-child policy and comprehensive two-child policy[9]. To a great extent, the gender of onechild can influence the further fertility willingness of the childbearing age group, and the fertility willingness of the sample is lower under the background of comprehensive two-

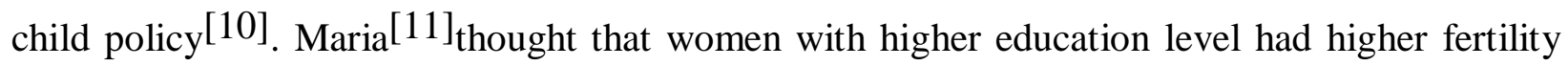

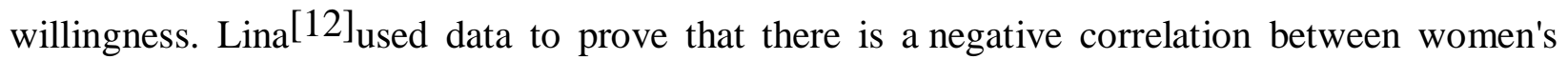
education level and fertility willingness. The relationship between education level and fertility willingness was inverted U-shaped, but nonlinear[13]. According to Huang Xiunv[14], the healthier the child-bearing age group is, the better their subjective well-being will be, and theywill have a positive attitude towards the future, which will help them choose to have two children.

In the study of social factors, social class can be regarded as the relationship between class identity and fertility willingness, which can be positively correlated or negatively correlated, The 


\section{International Journal of Social Science and Economic Research}

ISSN: $2455-8834$

Volume:06, Issue:03 "March 2021"

higher the degree of identity, the basic conditions for fertility are met, and they are willing to choose to have more births, but other influences may be considered to reduce fertility willingness[15]. Public services play an active role in children's education, medical care, employment and social security, which can greatly alleviate the cost of childbearing, and then affect the fertility willingness. Social security lies in the research on the relationship between fertility willingness, It is considered that social security has a positive correlation with fertility willingness under certain conditions, but it has no significant impact ${ }^{[16]}$,However, in most research results, social security has a negative correlation with fertility willingness, thus reducing the fertility rate because ofits substitution effect with children's intergenerational support.

Economic factors have a great influence on fertility willingness. The cost of giving birth and raising children is high, including indirect costs such as the direct cost of raising children and the time cost, When the family income is limited, the family's economic burden is heavy, which leads

to the reluctance of most families to choose to have two children ${ }^{[17]}$.Lina $\left.{ }^{[12}\right]_{\text {obtained the }}$ following results based on CGSS data analysis in 2013, There is a positive correlation between family-owned property and fertility willingness, while there is no linear correlation between personal income and women's fertility willingness.

In the study of policy concept factors, people's fertility concept is a subjective attitude, and many factorshave an effect on fertility willingness [18]. The impact of the two-child policy promulgated by the governmenton people's fertility willingness is limited, For those who have strong fertility willingness, the promulgation of the two-child policy has a great impact on them and effectively promotes the growth of population fertility rate ${ }^{[19]}$. With the rapid development of China's oldage security, parents reduce their economic dependence on other responsible subjects by receiving pensions, and the concept of raising children and preventing old age gradually fades, which may have a crowding-out effect on fertility willingness [20].

\section{Data and Methods}

\subsection{Data Sources}

statistical data of Chinese General Social Survey questionnaire in 2015, which is a continuous cross- sectional survey conducted by China Survey and Data Center of Renmin University of China, which uses scientific sampling and household visits to more than 10,000 families in China every year, with a total of 10,968 questionnaires collected. The questionnaire covers six modules in 31 provinces, cities and autonomous regions of China, involving multi-level components such as society, family and individual, forming the earliest nationwide, comprehensive and continuous 


\section{International Journal of Social Science and Economic Research}

ISSN: $2455-8834$

Volume:06, Issue:03 "March 2021"

academic survey project in China, and becoming the most important data source basis for the study of society, family and individual in China.

Considering the data validity of the study on influencing factors of fertility willingness under the comprehensive two-child policy in this study, after deleting the missing value of using sample variables, there are 2251 valid samples.

\subsection{Variable Setting}

\subsubsection{Dependent Variable}

The dependent variable is the fertility willingness under the comprehensive two-child policy. Using CGSS2015 questionnaire, "If there is no policy restriction, how many children would you like to have?". The variable processing method is that the samples with the number of children " 0 " and "1" in the questionnaire are set to have no fertility willingness, and they are assigned "0"; When the respondents chooseto fill in the number of children greater than or equal to 2 , they are set to have fertility willingness, and the value is " 1 ".

\subsubsection{Independent Variables}

The independent variables are population factor, social factor, economic factor and policy concept. Variable selection have gender a2, household s1, age, health status a15, education level a7a, population a63, after ten years of social hierarchy a433, infrastructure construction satisfaction b169, social security satisfaction b166, labor employment satisfaction b165, social management and service satisfaction b164, housing satisfaction b163, health service satisfaction b162, public education satisfaction b161, whether to participate in the basic medical insurance a611, basic pension a612, commercial medical treatment a613, and commercial endowment a614,economic status a64, Family income a62, property ownership a65, housing area a11; Pension liability a41, government intervention a47. The selection and assignment results of dependent variables and independent variables are shown in Table 1 below.

\subsection{Model}

SPSS 22.0 software was used for statistical analysis of data, The basic data characteristics of demographic characteristics, social factors, economic factors and policy concepts, and fertility willingness were grasped through descriptive statistics, Binary logistic regression method was selected to analyze the influencing factors of fertility willingness under the background of two children. The Logistic model was put forward by Mc Fadden in 1973, which uses Logistic probability distribution function, through Logistic transformation, the function can be written as logit model of Logistic regression: 


\section{International Journal of Social Science and Economic Research}

ISSN: $2455-8834$

Volume:06, Issue:03 "March 2021"

$$
\mathrm{E}(\mathrm{y})=\operatorname{logitp}=\ln \left(\frac{p}{1-p}\right)=\beta_{0}+\beta_{1} X_{1}+\beta_{2} X_{2}+\cdots \beta_{n} X_{n}
$$

According to the dependent and independent variables selected in this paper, $y$ represents the value of sample fertility willingness under the background of comprehensive two-child policy, $\beta n$ represents the coefficient of regression model equation, $\beta 0$ is the constant term of regression equation, $X n$ represents the selected independent variable, and there are 25 variables in four dimensions.

\subsection{Descriptive Statistical Analysis}

In demographic characteristics, the average age is 45.741 years old, the minimum age is 24 years old, and the maximum age is 86 years old, It is generally considered that women's 15-49 years old is the better childbearing age $[21]$. The average health status of the population is 4.010 , which indicates that the survey sample is in a relatively healthy state and has a good fertility foundation. The average education level of ordinary high schools is 6, among which the education level lower than and including ordinary high schools accounts for $60.5 \%$, and the undergraduate degree or above accounts for $32.6 \%$, The overall education levelof the samples is low, which affects the fertility willingness of the samples in the context of the comprehensive two-child policy to a certain extent. The survey sample has an average of 5 for which level it will be in in the next ten years, accounting for $74.5 \%$ in the higher than the fifth level, which can provide a good foundation for having two children in the future. In the satisfaction scores of public services, the average scores of infrastructure construction b169, social security b166, labor and employment b165, social management service b164, housing security b163, medical and health service b162 and public education b161 are all above 60 points, and $92.5 \%$ and $73.4 \%$ of the samples participated in basic medical security and basic old-age security respectively,82.2\% and $86.9 \%$ chose not to buy commercial medical insurance and commercial endowment insurance, respectively,Public services and social security play an important role in ensuring fertility willingness and can provide a good social environment, The overall satisfaction of public services is low in the survey sample, so there is still much room for improvement in the construction of public services. The average value of pension responsibility is 2.68 , which is mainly responsible for children's future pension responsibility, accounting for the highest $49.9 \%$ in the sample, with government pension accounting for $7.1 \%$, elderly self-responsibility accounting for $4.9 \%$, and government/children/elderly tripartite pension responsibility accounting for $38.1 \%$, In the survey sample, children's pension has become the main body of future pension, which has certain influence on fertility willingness. 
International Journal of Social Science and Economic Research

ISSN: 2455-8834

Volume:06, Issue:03 "March 2021"

Table 1 Variable Definition and Descriptive Statistics

\begin{tabular}{|c|c|c|c|c|c|c|c|}
\hline category & dimension & $\begin{array}{l}\text { Variable } \\
\text { selection }\end{array}$ & Variable assignment & $\begin{array}{l}\text { averagemean } \\
\text { value }\end{array}$ & $\begin{array}{l}\text { standard } \\
\text { deviation }\end{array}$ & $\begin{array}{l}\text { Minimum } \\
\text { value }\end{array}$ & $\begin{array}{l}\text { peak } \\
\text { value }\end{array}$ \\
\hline \multirow{9}{*}{$\begin{array}{l}\text { dependent } \\
\text { variable }\end{array}$} & & Fertility & $0=$ none $; 1=$ yes & 0.768 & 0.422 & 0 & 1 \\
\hline & & desire & & & & & \\
\hline & demographic & $\mathrm{a} 2$ & $1=$ male $; 2=$ female & 1.550 & 0.498 & 1 & 2 \\
\hline & factor & & & & & & \\
\hline & & s1 & $1=$ city $; 2=$ rural areas & 1.190 & 0.390 & 1 & 2 \\
\hline & & age & numerical value & 45.741 & 0.197 & 24 & 86 \\
\hline & & a15 & $1-5$ very not-very healthy & 4.010 & 0.905 & 1 & 5 \\
\hline & & $\mathrm{a} 7 \mathrm{a}$ & 1-13 Education level & 6.550 & 3.383 & 1 & 13 \\
\hline & & a63 & numerical value & 3.240 & 1.679 & 1 & 13 \\
\hline \multirow{18}{*}{$\begin{array}{l}\text { Independent } \\
\text { Variables }\end{array}$} & social factor & a433 & 1-10 lowest-highest level & 5.070 & 3.403 & 1 & 10 \\
\hline & & & & & & & \\
\hline & & b169 & Numerical score & 67.940 & 20.044 & 0 & 100 \\
\hline & & b166 & Numerical score & 65.680 & 19.830 & 0 & 100 \\
\hline & & b165 & Numerical score & 63.133 & 20.254 & 0 & 100 \\
\hline & & b164 & Numerical score & 66.200 & 19.219 & 0 & 100 \\
\hline & & b163 & Numerical score & 61.110 & 23.137 & 0 & 100 \\
\hline & & b162 & Numerical score & 66.837 & 18.997 & 0 & 100 \\
\hline & & b161 & Numerical score & 70.410 & 19.397 & 0 & 100 \\
\hline & & a611 & $\begin{array}{l}1=\text { participate } ; 2=\text { not } \\
\text { participate }\end{array}$ & 1.060 & 0.381 & 1 & 2 \\
\hline & & a612 & $\begin{array}{l}1=\text { participate } 2=\text { not } \\
\text { participate }\end{array}$ & 1.240 & 0.578 & 1 & 2 \\
\hline & & $\mathrm{a} 613$ & $\begin{array}{l}1=\text { participate } 2=\text { not } \\
\text { participate }\end{array}$ & 1.760 & 0.783 & 1 & 2 \\
\hline & & a614 & $\begin{array}{l}1=\text { participate } ; 2=\text { not } \\
\text { participate }\end{array}$ & 1.790 & 0.856 & 1 & 2 \\
\hline & $\begin{array}{l}\text { economic } \\
\text { factor }\end{array}$ & a64 & $\begin{array}{l}\text { 1-5 Far low-Far high } \\
\text { average level }\end{array}$ & 2.770 & 1.069 & 1 & 5 \\
\hline & & $\mathrm{a} 62 *$ & numerical value & 1.051 & 2.755 & 0 & 904.8 \\
\hline & & $\mathrm{a} 65$ & numerical value & 1.080 & 0.884 & 0 & 6 \\
\hline & & a11 & numerical value & 113.681 & 84.586 & 5 & 1050 \\
\hline & $\begin{array}{l}\text { Policy } \\
\text { concept }\end{array}$ & $\mathrm{a} 41$ & $\begin{array}{c}\text { 1=government } ; 2=\text { children; } \\
3=\text { old people } 4=\text { shared } \\
\text { equally }\end{array}$ & 2.680 & 1.326 & 1 & 4 \\
\hline
\end{tabular}


International Journal of Social Science and Economic Research

ISSN: 2455-8834

Volume:06, Issue:03 "March 2021"

a47

1-5 totally disagree- $\quad 2.590$

1.380

5

totally agree

Note: * Family income unit is 10,000

\subsection{Result}

The demographic characteristics, social factors, economic factors, and policy concept factors were regressed by binary logistic regression with sample fertility willingness under the background of comprehensive two-child policy, and the Wald step-by-step method was used to enter the equation, The results are shown in Table 2. The following 9 variables have significant influence on fertility willingness. Age, family population a63, social class a433 after ten years, satisfaction with social management service b164, satisfaction with infrastructure construction b169, property ownership a65 and housing area a11 have positive and significant impacts on fertility willingness, while education level a7a and social security satisfaction b166 have significant negative correlations on fertility willingness. The binary logistic regressionequation is:

$\mathrm{Y}=1.198+0.016 \mathrm{age}+0.007 \mathrm{~b} 1690.009 \mathrm{~b} 166+0.011 \mathrm{~b} 164+0.146 \mathrm{a} 63+0.181 \mathrm{a} 65+0.057 \mathrm{a} 433+0.002 \mathrm{a} 1$ 1- $0.046 a 7 a$.

There was a positive correlation between age and fertility intention $(\mathrm{P}=0.007)$. For every additional unit of age, the fertility willingness of the sample increases by 0.016 units under the background of the comprehensive two-child policy, which indicates that loneliness gradually increases with the increase of age, and despite the decline of physical function, it will place hope on fertility and have a higher fertility willingness, which leads to the phenomenon of getting old in real life. There is a significant positive correlation between family population a63 and fertility intention $(\mathrm{P}=0.001)$. When there is a large number of families, we can feel the increase of happiness brought by the family population, and establish a positive concept of fertility, which is conducive to improving fertility willingness. There is a significant positive correlation between future social class a433 and fertility willingness, with a P value of 0.000 . Children's growth and cultivation need cost, and the higher the social level in the future, which indicates that the childbearing age group has the ability to be responsible for the second child and can have a positive effect on fertility willingness, For every additional unit level in the social level, the fertility willingness of the sample increases by 0.057 in the context of the comprehensive twochild policy. The more satisfied we are with social management service b164 and infrastructure construction b169, the better guarantee can be provided, which is beneficial to increase fertility willingness in a good social environment, and the impact on social management service satisfaction and fertility willingness $(\mathrm{P}=0.004)$ is higher than that between infrastructure construction satisfaction and fertility willingness $(\mathrm{P}=0.046)$, The infrastructure in China is 


\section{International Journal of Social Science and Economic Research}

ISSN: $2455-8834$

Volume:06, Issue:03 "March 2021"

relatively perfect after long-term construction, and the community has higher expectations for social management services. Owning property a65 and housing area a11, as economic influencing factors, have a significant positive correlation with fertility intention. The more houses a family owns $(\mathrm{P}=0.003)$, the larger its housing area $(\mathrm{P}=0.007)$, and the stronger its fertility will be, For every additional house property, the fertility will increase by 0.181 units, and for every additional housing area, the fertility will increase by 0.002

units. This shows that in China, with the improvement of housing conditions, the economic strength of marriage and childbearing groups has increased, and they are more willing to choose to have two children, Their families can provide a good housing environment and living care conditions for future generations, and can guarantee their present and even future life happiness $[22]$.

Education level a7a was negatively correlated with fertility intention, with a $\mathrm{P}$ value of 0.003 . For every unit of education improvement, the fertility willingness decreases by 0.046 units. This shows that with the higher education of childbearing age groups, their fertility willingness decreases, while individuals with lower education level tend to choose more children. When the school-age group still receives school education, it will delay the marriage time, and its fertility level will show a downward trend, thus reducing the birth rate of future generations [23]. Education level can play an important role in the preference of fertility willingness, while higher education level can reduce the desire of fertility willingness and control the family size. Women with higher education can play a role in weakening gender discrimination in the labor market, and can improve their bargaining power in the family, so they have the right to speak in having children. College-educated school-age groups think that their work is busy and their relative time and energy are less, which has a negative relationship with fertility intention. With the optimization of educational resources, receiving a long and good education will make people tend to be independent, increase the cost of reproductive opportunities and reduce the demand for fertility, Secondly, due to the influence of educational resources premium, based on Becker's substitution model of quantity and quality, more childbearing age groups tend to choose to concentrate resources to train their children, thus reducing their fertility willingness ${ }^{[24]}$. There is a significant negative correlation between social security satisfaction b166 and fertility intention $(\mathrm{P}=0.018)$. When the social security is perfected and improved, the fertility will be reduced to a certain extent. Social security has a substitution effect on the traditional concept of raising children and preventing old age, and the self-insurance family model gradually changes to the social safety net model, which greatly affects the fertility willingness and reduces the number of births, but the improvement of socialsecurity inhibits the fertility willingness. 
International Journal of Social Science and Economic Research

ISSN: 2455-8834

Volume:06, Issue:03 "March 2021"

Table 2 Results of Binary logistic Regression Analysis on Influencing Factors of Fertility Willingnessunder Comprehensive Two-Child Policy

\begin{tabular}{cccccccc}
\hline variable & B & S.E. & df & significance & $\operatorname{Exp}(\mathrm{B})$ & \multicolumn{2}{c}{ 95\% confidence interval } \\
\cline { 5 - 7 } & & & & & & $\begin{array}{c}\text { upper } \\
\text { limit }\end{array}$ & lower limit \\
& & & & & & & \\
\hline age & 0.016 & 0.006 & 1 & 0.007 & 1.016 & 1.004 & 1.028 \\
b169 & 0.007 & 0.004 & 1 & 0.046 & 0.993 & 0.986 & 1.000 \\
b166 & -0.009 & 0.004 & 1 & 0.018 & 0.991 & 0.983 & 0.998 \\
b164 & 0.011 & 0.004 & 1 & 0.004 & 1.011 & 1.004 & 1.019 \\
a63 & 0.146 & 0.043 & 1 & 0.001 & 1.158 & 1.065 & 1.258 \\
a65 & 0.181 & 0.061 & 1 & 0.003 & 0.834 & 0.740 & 0.941 \\
a433 & 0.057 & 0.014 & 1 & 0.000 & 1.058 & 1.029 & 1.088 \\
a11 & 0.002 & 0.001 & 1 & 0.007 & 1.002 & 1.001 & 1.004 \\
a7a & -0.046 & 0.016 & 1 & 0.003 & 0.968 & 0.938 & 0.999 \\
constant & 1.198 & 0.050 & 1 & 0.000 & 1.323 & & \\
\hline
\end{tabular}

\section{Conclusions and Suggestions}

First, there is a negative correlation between education level and fertility willingness. Groups with lower education level have limited knowledge and are more likely to choose to have more children because of the influence of traditional fertility concept, and this group has stronger fertility willingness; The higher the

education level, the richer the knowledge system, and the conditions for establishing the concept of fertility in line with their own situation, the lower their fertility willingness. Groups with higher education level are more likely to match each other and form families, while men and women with higher education level tend to choose to establish modern fertility concept. From the perspective of economic rationality, the group with higher educational background tends to cultivate the quality of offspring children in the quantity and qualityof their children, and will not blindly pursue the quantity of offspring children. In addition, highly educated groups should pay attention to the quality of life and pursue the realization of self-worth, which makes it difficult to strike a balance between family and career, thus reducing their fertility willingness. Secondly, there is a negative correlation between social security and fertility willingness. The research on the influence of social security on fertility willingness shows that social security has a negative impact on improving fertility willingness, and social security weakens the traditional concept of raising children and preventing old age,In countries with higher social security level, it has been proved that higher social security can alleviate the pressure of providing for the aged and greatly reduce the fertility rate. Finally, age, family size, social class after ten years, satisfaction with 


\section{International Journal of Social Science and Economic Research}

ISSN: $2455-8834$

Volume:06, Issue:03 "March 2021"

social management services, satisfaction with infrastructure construction, ownership of real estate and housing area, and fertility willingness have significant positive effects. Based on this, the following suggestions are put forward:

Adjust the birth policy and actively guide it. Constantly making policy adjustments to the implementation of the comprehensive two-child policy and truly implementing the comprehensive two-child policy is not only to ease the restrictions on the number of children, but the state and the government need to issue more detailed implementation rules for the follow-up related birth policies as soon as possible to reduce the expected cost of the birth policy and effectively protect the interests of groups with higher fertilitywillingness, In addition, establish and improve the realtime supervision and effect evaluation mechanism for the birth policy, effectively make adjustments, and guide from the state, society and individuals, so as to improve the fertility rate and solve the severe population problem.

Improve the social security system to protect the rights and interests related to fertility. One of the important reasons for the low fertility willingness is the imperfection of social security and the heavy burdenof social security contributions, which weakens fertility willingness. It is necessary to improve the social security system, pay attention to the health and career development of women's fertility, improve the medical security in fertility, allocate medical resources in a balanced way, and ensure that women and their children receive high-quality medical services. Adjust the maternity leave system in a timely manner, and extend the paid leave time for men and women on the premise of feasibility, so as to ensure that men and women share the family responsibility of raising children. In the job market, we should build a friendly employment environment, eliminate employment discrimination such as gender, marriage and childbearing as much as possible, improve competitiveness, solve the worries of women's fertility, and reduce the unemployment risk after giving birth, thus providing a solid foundation and guarantee for the continued implementation and implementation of China's fertility policy.

Improve the economic environment and reduce the burden of childcare. When there is a good economic environment and foundation, the fertility will increase significantly. The higher housing cost brings too mucheconomic pressure to the parenting families, and inhibits the reproductive behavior. Therefore, for families with high fertility willingness, the state and the government can appropriately introduce a series of corresponding financial subsidies and support policies, reduce preferential policies such as tax payment standards for groups, and appropriately subsidize their housing, water and electricity costs, so as to reduce the raising costs and reduce the economic burden brought by parenting.

\section{References}


International Journal of Social Science and Economic Research

ISSN: 2455-8834

Volume:06, Issue:03 "March 2021"

[1] Xiaotian,Feng.Study on the Influencing Factors of Sample Fertility Willingness under the Background of Comprehensive Two-Child Policy [J].Journal of Southeast University (Philosophy and Social Science), 2017,19(03):75-82+147+149.

[2] Leibenstein,Harvey.Beyond Economic Man:Economics,Politics, and the Population Problem[J].Population and Development Review.1977,3(3):183-199.

[3] Jennifer S. Barber; Susan A. Murphy; William G. Axinn; Jerry Maples.6,Discrete-Time Multilevel Hazard Analysis[J].Sociological Methodology.2000,30(1):201-235.

[4] Becker,G.S. The Economic Approach to Human Behavior. University of Chicago Press Economics Books 4(4),1976.

[5] Caldwell, John C.Toward A Restatement of Demographic Transition Theory[J].Population and Development Review.1976,2(3-4):321-366.

[6] Bin,Zhou.Analysis of fertility willingness and influencing factors of women of childbearing age in Jiangxi Province under the comprehensive two-child policy [J]. Northwest Population Journal,2018,39(06):96-105.

[7] Jian,Song.Pension ability and pension risk of "421" family-also on family safety and building a harmonious society [J]. Journal of Renmin University of China,2013,27(05):94102.

[8] Xin, Yuan.Evolution of China's birth policy and balanced population development Thinking from one- child policy to comprehensive two-child policy [J]. Population Journal,2016,38(05):5-14.

[9] Jianghong,Lv.,Baofeng,Huang.,Shenglin,Shi.Comparison of fertility willingness of women of childbearing age in one-child and two-child families [J]. Population Journal,2013(01):36-43.

[10] Liang,Ma.,Xingming,Fang.,Zhen,Lei.,Xiaochen,Cai.Will the sex of the only child affect parents' willingness to have a second child?-Research based on China Comprehensive Social Survey (CGSS) data [J].Population Journal,2016,38(06):17-26.

[11] Maria Letizia Tanturri; Letizia Mencarini; Katia Begall; Melinda Mills.Gender equity and fertility intentions in Italy and the Netherlands[J].Demographic Research.2008,18(1):1.

[12] Lina,Zhang.Socio-economic Status, Subjective Flow Perception and Sample Fertility 
International Journal of Social Science and Economic Research

ISSN: 2455-8834

Volume:06, Issue:03 "March 2021"

Willingness of Women of Childbearing Age under the Background of Comprehensive TwoChild Policy: An Empirical Study Based on CGSS2013 Data [J]. Journal of Xihua University(Philosophy \& Social Sciences),2018,37(03):40-48.

[13] Mingshuai,He.,Miao, Yu.Family per capita income, intergenerational social mobility and fertility willingness [J]. Studies in Labor Economics,2017,5(05):117-140.

[14] Xiu-nv,Huang.,Sheng-li, Guo.,Hao,Zhang.Synergy or crowding out: analysis of the influence of support pressure on the fertility willingness of floating population under the background of comprehensive two- child policy [J]. Modern Finance and EconomicsJournal of Tianjin University of Finance and Economics,2018,38(05):30-41.

[15] Chong, Zhang., Yuxiu,Chen.,Haiya,Liao.Study on the influencing factors of sample fertility willingness of Chinese women of childbearing age under the background of comprehensive two-child policy-Based on CGSS data analysis in 2015 [J].Population and Society,2019,35(05):71-80.

[16] Leran Wang.Fertility and unemployment in a social security system[J].Economics Letters,2015:19-23.

[17] Han,Lei.,Longpeng,Tian. Fertility Desire and Fertility Behavior of "All-round Two-child"Based on the survey data of Xiangtan City in 2014 [J].Journal of Xiangtan University (Philosophy and Social Sciences Edition),2016,40(01):51-56.

[18] Rong,Chen.,Baochang,Gu.The 30-year evolution of fertility willingness in Shanghai [J]. Population and Society,2014,30(01):49-54+71.

[19] Yiming,Wang.,Xuexin, Zhou.,Guizhong, Tang.,Zhongchen,He. Study on sample fertility willingness and influencing factors of women of childbearing age in Chongqing under the background of comprehensive two-child policy [J]. Modern Preventive Medicine,2017,44(23):4271-4275.

[20] Huan, Chen., Yuehua, Zhang.Research on the Influence of Endowment Insurance on Fertility Willingness: An Empirical Analysis Based on CGSS Data [J]. Insurance Studies, 2019(11):88-99.

[21] Cungang, Zhang.,Daotian, Mei.Ideal and Reality: Fertility Willingness and Actual Behavior of Chinese Urban Women of Childbearing Age-An Empirical Analysis Based on CGSS Data in 2010 and 2015 [J]. Northwest Population Journal,2020,41(04):38-46. 
International Journal of Social Science and Economic Research

ISSN: 2455-8834

Volume:06, Issue:03 "March 2021"

[22] Yajun, Qiao.Study on sample fertility willingness and influencing factors of occupational childbearing age groups under the background of comprehensive two-child policyAnalysis based on CGSS2015 data [J]. Review of Economic Research,2019(17):108-116.

[23] Andaleeb A,Baez et al,Does Cash for School Influence Young Women's Behavior in the Longer Term?Evidence from Pakistan[R].IZA Discussion Papers,NO.5703,2011.

[24] Diebolt,Claude;Menard,Audrey-Rose;Perrin,Faustine.Behind the fertility-education nexus: what triggered the French development process?[J].European Review of Economic History,2017, 21(4):357-392. 